\title{
Maximum Power Point Tracking of Wind Turbine Conversion Chain Variable Speed Based on DFIG
}

\author{
H. Becheri ${ }^{1}$, I. K. Bousarhanne ${ }^{2}$, A. Harrouz ${ }^{3}$, H. Glaoui ${ }^{4}$, T. Belbekri ${ }^{5}$ \\ ${ }_{1,2,4,5}$ Department of Technologie, Faculty of Techologie, University of Bechar, Algeria \\ ${ }^{3}$ Department of Hydrocarbon and Renewable Energy, Faculty of Science and Technology, University of Draïa, Algeria
}

\begin{tabular}{l}
\hline \hline Article Info \\
\hline Article history: \\
Received Oct 8, 2017 \\
Revised Dec 10, 2017 \\
Accepted Jan 23, 2018 \\
\hline Keyword: \\
DFIG \\
Fifth keyword \\
MPPT \\
Power supply \\
Vector control
\end{tabular}

\begin{abstract}
Wind energy has many advantages, it does not pollute and it is an inexhaustible source. However, the cost of this energy is still too high to compete with traditional fossil sources. The yield of a wind turbine depends on three parameters: the power of the wind, the turbine power curve and the ability of the generator to respond to fluctuations in the wind. This article presented the MPPT of a wind turbine system equipped with an asynchronous generator has dual power under Matlab Simulink program, in the first time we simulated all the conversion chain with complete model of DFIG and vector control in second step then applied the extracted maximum power MPPT strategists, this command is effective and has several advantages it offered to kept the maximum power delivered to network despite all the parameter is change.
\end{abstract}

Copyright $(0) 2018$ Institute of Advanced Engineering and Science. All rights reserved.

\section{Corresponding Author:}

Houcine Becheri,

Departement of Technologie, Faculty of Techologie,

Tahri Mohamed University,

University Tahri Med, Street Knadssa, Bechar 08000, Algeria

Email: houcine.becheri@gmail.com

\section{INTRODUCTION}

Electrical energy is crucial to any socio-economic development [1]. The demand for electricity is very important to this dilemma, it is necessary to appeal to new energy sources that will be without consequence for man and environment. Wind energy represents a sizeable potential for bearing damping demand increasingly rampant, after centuries of evolution and further research in recent decades and some wind power projects developed by major central wind turbines provide electricity in parts of the world at a competitive price than the energy produced by conventional plants [2].

Today, the development and proliferation of wind turbines have led researchers in Electrical Engineering to conduct investigations in order to improve the efficiency of electromechanical conversion and quality of the energy supplied [3]. It is in this context that this paper describes that we present a study on the use of asynchronous machines has dual power in a wind system. Initially modeling and conversion system simulation (turbine and asynchronous generator dual feed)

Then the vector control in stator active and reactive powers are proposed in a last step And improved the system study and extract maximum power presents MPPT strategists and the simulation results. The objective of this paper is to develop a novel combined MPPT-pitch angle control system of a variable speed wind turbine. 


\section{MODELLING WIND POWER SYSTEM}

\subsection{Model of the wind turbine}

The wind turbine collects the kinetic energy of the wind and converts it into a torque, which turns the blades of the rotor [3]. In our study, this system used a wind turbine based on DFIG, which supplies to generate the torque required to the load in Figure 1.

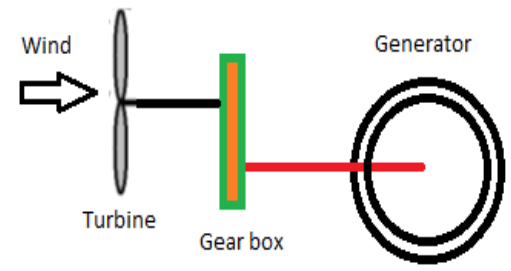

Figure 1. Schematic of the wind turbine

\subsubsection{Wind modeling}

In our case, the wind speed will be modeled as a sum of several harmonics [5]:

$V(t)=10+0.2 \sin (0.1047 t)+2 \sin (0.2665 t)+\sin (1.2930 t)-0.2 \sin (3.6645 t)$

\subsubsection{Aaerodynamic power}

$P_{t}=\frac{1}{2} \cdot C_{p}(\lambda, \beta) \cdot \rho \cdot S \cdot v^{3}$

Which $\square$ is defined by: $\lambda=\frac{\Omega_{t} \cdot R}{v}$

The coefficient of power $\mathrm{Cp}$ represents the aerodynamic efficiency of the wind turbine. We will use an approximate expression of the power coefficient given by [6]:

$\left.C_{p}(\lambda, \beta)=(0.35-0.00167)\right) \cdot(\beta-2) \cdot \sin \left[\frac{\pi \cdot(\lambda+0.1)}{14.34-0.3 \cdot(\beta-2)}\right]-0.000184 \cdot(\lambda-3) \cdot(\beta-2)$

The simulation of the power coefficient is shown in Figure 2:

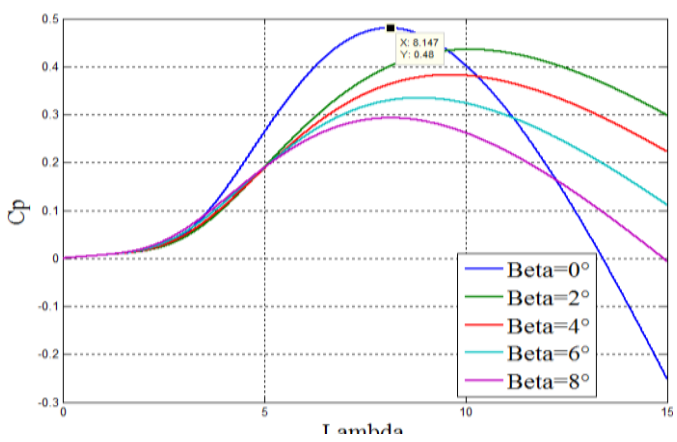

Figure 2. $\mathrm{Cp}(\lambda, \beta)$ Characteristics for various values of pitch angle $\beta$

The aerodynamic torque is expressed as follows:

$C_{t}=\frac{P_{t}}{\Omega_{t}}=\frac{\pi}{2 \cdot \lambda} \rho \cdot R^{3} \cdot v^{2} \cdot C_{p}(\lambda, \beta)$ 
For the mechanical part can thus lead to a more simple mechanical model [7 and 14] (Figure 3). The dynamic behavior of the generator can be represented by the following equation:

$J \frac{d w}{d t}=T_{e}-T_{e m}-f_{m} w$

Where $J t$ is the rotational moment of inertia of the rotor and the generator $\mathrm{kg} \cdot \mathrm{m}^{2}, \omega$ is the angular velocity of the rotor in red $/ s, T_{e}$ is the mechanical torque applied to the alternator shaft in $\mathrm{Nm}, T_{e m}$ is the electromagnetic torque developed by the generator in $\mathrm{Nm}$ and $f_{m}$ is the viscous friction coefficient in $\mathrm{Nm}$.

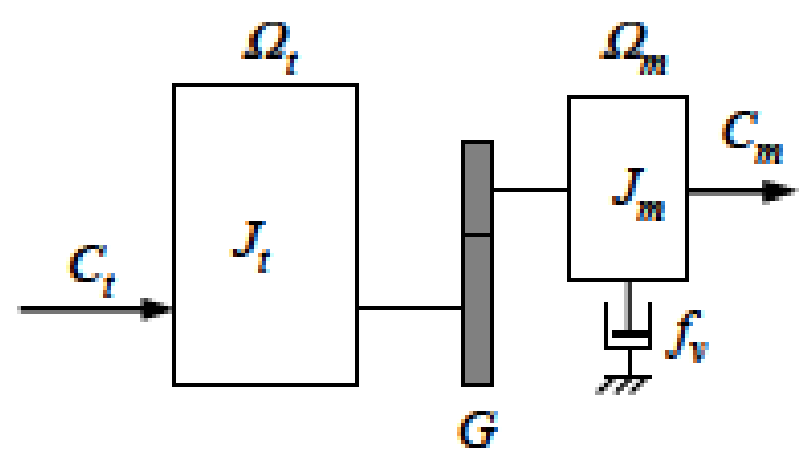

Figure 3. Mechanical model of turbine

\subsection{DFIG Modeling}

We modeled the DFIG with the implementation of the transformation of the park following Repository related rotating field This repository is called system of axes (X, Y), it rotates with the speed of the electromagnetic field is obtained [9]:

The stator: $\quad\left\{\begin{array}{c}\mathrm{u}_{\mathrm{ds}}=\mathrm{R}_{\mathrm{s}} \mathrm{i}_{\mathrm{ds}}+\frac{\mathrm{d} \varphi_{\mathrm{ds}}}{\mathrm{dt}}-\omega_{\mathrm{s}} \varphi_{\mathrm{qs}} \\ \mathrm{u}_{\mathrm{qs}}=\mathrm{R}_{\mathrm{s}} \mathrm{i}_{\mathrm{qs}}+\frac{\mathrm{d} \varphi_{\mathrm{qs}}}{\mathrm{dt}}+\omega_{\mathrm{s}} \varphi_{\mathrm{ds}} \\ \mathrm{u}_{\mathrm{os}}=\mathrm{R}_{\mathrm{s}} \mathrm{i}_{\mathrm{os}}+\frac{\mathrm{d} \varphi_{\mathrm{os}}}{\mathrm{dt}}\end{array}\right.$

The rotor: $\quad\left\{\begin{array}{c}\mathrm{u}_{\mathrm{dr}}=\mathrm{R}_{\mathrm{r}} \mathrm{i}_{\mathrm{dr}}+\frac{\mathrm{d} \varphi_{\mathrm{dr}}}{\mathrm{dt}}-\left(\omega_{\mathrm{s}}-\omega_{\mathrm{r}}\right) \varphi_{\mathrm{qr}} \\ \mathrm{u}_{\mathrm{qr}}=\mathrm{R}_{\mathrm{r}} \mathrm{i}_{\mathrm{qr}}+\frac{\mathrm{d} \varphi_{\mathrm{qr}}}{\mathrm{dt}}+\left(\omega_{\mathrm{s}}-\omega_{\mathrm{r}}\right) \varphi_{\mathrm{dr}} \\ \mathrm{u}_{\mathrm{or}}=\mathrm{R}_{\mathrm{s}} \mathrm{i}_{\mathrm{or}}+\frac{\mathrm{d} \varphi_{\mathrm{or}}}{\mathrm{dt}}\end{array}\right.$

The equations of flow and after the simplification are:

$\left\{\begin{array}{c}\varphi_{\mathrm{ds}}=\mathrm{L}_{\mathrm{s}} \mathrm{i}_{\mathrm{ds}}+\mathrm{Mi}_{\mathrm{dr}} \\ \varphi_{\mathrm{qs}}=\mathrm{L}_{\mathrm{s}} \mathrm{i}_{\mathrm{qs}}+\mathrm{Mi}_{\mathrm{qr}} \\ \varphi_{\mathrm{os}}=\mathrm{L}_{\mathrm{s}} \mathrm{i}_{\mathrm{os}}\end{array}\right.$

Also for the rotor and in the same way are:

$\left\{\begin{array}{c}\varphi_{d r}=L_{r} i_{d r}+M i_{d s} \\ \varphi_{q r}=L_{r} i_{q r}+M i_{q s} \\ \varphi_{o r}=L_{r} i_{o r}\end{array}\right.$ 
Doubly-Fed Induction Generator model of the landmark Park in the form of state:

$$
\left\{\begin{array}{c}
\frac{d i_{d s}}{d t}=\frac{1}{L_{s} \sigma}\left(u_{d s}-R_{s} i_{d s}+\frac{M R_{r}}{L_{r}} i_{d r}+\left(\omega_{s} \sigma-P \Omega_{r}(\sigma-1)\right) L_{s} i_{q s}-\frac{M}{L_{r}} u_{d r}+P \Omega_{r} M i_{q r}\right) \\
\frac{d i_{q s}}{d t}=\frac{1}{L_{s} \sigma}\left(u_{q s}-R_{s} i_{q s}+\frac{M R_{r}}{L_{r}} i_{q r}+\left(\omega_{s} \sigma-P \Omega_{r}(\sigma-1)\right) L_{s} i_{d s}-\frac{M}{L_{r}} u_{d r}+P \Omega_{r} M i_{q r}\right) \\
\frac{d i_{d r}}{d t}=\frac{1}{L_{s} \sigma}\left(u_{d r}-R_{r} i_{d r}+\frac{M R_{r}}{L_{s}} i_{d s}+\frac{\sigma-1}{M} P \Omega_{r} L_{s} L_{r} i_{q s}-\frac{M}{L_{s}} u_{q s}+\frac{\omega_{s} \sigma-P \Omega_{r}}{L_{s}} i_{q r}\right) \\
\frac{d i_{q r}}{d t}=\frac{1}{L_{r} \sigma}\left(u_{q r}-R_{r} i_{q s}+\frac{M R_{s}}{L_{s}} i_{q s}+\left(\omega_{s} \sigma+P \Omega_{r}\right) L_{r} i_{d r}-\frac{M}{L_{r}} u_{q s}+P \Omega_{r} M i_{d s}\right) \\
\frac{d \Omega_{r}}{d t}=-\frac{3 P M}{2 L_{r}}\left(\varphi_{d s} i_{q r}-\varphi_{q s} i_{d r}\right)-\frac{C_{r}}{j}-\frac{f_{r}}{j} \Omega_{r}
\end{array}\right.
$$

Where: $\sigma=1-\frac{\mathrm{M}^{2}}{\mathrm{~L}_{\mathrm{s}} \mathrm{L}_{\mathrm{r}}}$ is the dispersion coefficient.

The expression of the electromagnetic torque of the DFIG in reference Park [10]. The general form of electromagnetic torque is:

$C_{e m}=\frac{3 P M}{2 L_{r}}\left(\varphi_{d r} i_{q s}-\varphi_{q r} i_{d s}\right)=-\frac{3 P M}{2 L_{r}}\left(\varphi_{d s} i_{q r}-\varphi_{q s} i_{d r}\right)$

\subsection{Power Modeling DFIG}

\subsubsection{Modeling of phase rectifier diodes}

If we neglect the effect of encroachment, the rectifier output voltage will be defined as following:

$V_{\text {red }}(t)=\operatorname{Max}\left[V_{a}(t) \cdot V_{b}(t) \cdot V_{c}(t)\right]-\operatorname{Min}\left[V_{a}(t) \cdot V_{b}(t) \cdot V_{c}(t)\right]$

\subsubsection{Modeling of DC bus}

To reduce the ripple of the voltage source adding a low pass filter LC Their operation is governed by the following equations:

$\left\{\begin{array}{c}\frac{d I_{d}}{d t}=\frac{V_{r e d}-V_{D C}}{L_{f}} \\ \frac{d V_{D C}}{d t}=\frac{I_{d}-I_{S}}{c_{f}}\end{array}\right.$

\subsubsection{VDC Association to DFIG}

We will have the following system:

$\left[\begin{array}{l}V_{A} \\ V_{B} \\ V_{C}\end{array}\right]=\frac{V_{D C}}{3}\left[\begin{array}{ccc}2 & -1 & -1 \\ -1 & 2 & -1 \\ -1 & -1 & 2\end{array}\right] \cdot\left[\begin{array}{l}S_{1} \\ S_{1} \\ S_{1}\end{array}\right]$

In our case, the control of the switches of the inverter is performed by use of the command modulation or PWM pulse width.

\section{MAXIMUM POWER EXTRACTION TECHNIQUE}

The goal of the (MPPT) strategy is to pick up the maximum power from the wind; it involves the following of the power curve shown in Figure 4, given by in equation (15):

$P_{o p t}=\frac{1}{2} C_{p}^{o p t}\left(\lambda_{o p t}\right) \rho A V_{1}^{3}$ 


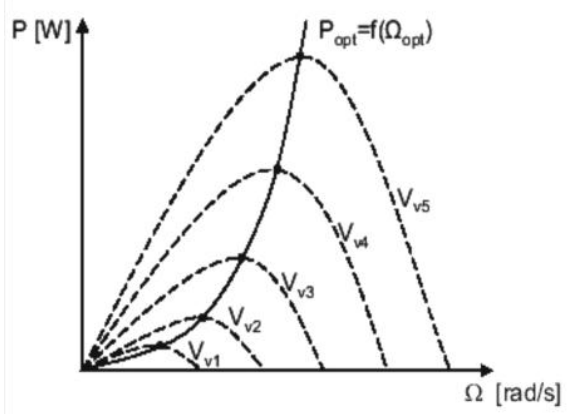

Figure 4. MPPT and power characteristics in function of mechanical speed

An erroneous speed measurement therefore inevitably leads to degradation of the power captured by the first extraction technique. This is why most wind turbines are controlled without control of the speed. This second control structure based on the assumption that the wind speed varies very little steady state.

\section{APPLICATION VECTOR CONTROL WITH THE ORIENTATION FLOW STATOR}

We consider the DFIG works in hypersynchronous mode, the principle is to direct the stator flux along the axis of the rotating frame [9].

So we have: $\varphi_{d s}=\varphi_{s}$ and we have: $\varphi_{q s}=0$ Relations between current stator and rotor currents:

The technical guidance of stator flux is applying on the couple become:

$C_{e}=-\frac{3}{2} P \frac{L_{m}}{L_{r}}\left(\varphi_{s d} \cdot I_{r q}\right)$

If neglecting the resistance of the stator winding R_S, voltage expressions become:

$C_{e}=-\frac{3}{2} P \frac{L_{m}}{L_{r}}\left(\varphi_{s d} \cdot I_{r q}\right)$

If neglecting the resistance of the stator winding R_S, voltage expressions become:

$$
\begin{gathered}
\left\{\begin{array}{c}
V_{s d}=0 \\
V_{s q}=V_{s}=\omega_{s} \cdot \varphi_{s d}
\end{array}\right. \\
\left\{\begin{array}{c}
\varphi_{s}=\varphi_{s d}=L_{s} \cdot I_{s d}+L_{m} \cdot I_{r d} \\
0=L_{s} \cdot I_{s q}+L_{m} \cdot I_{r q}
\end{array}\right.
\end{gathered}
$$

From this equation, we can write the equations linking the stator currents to the rotor currents:

$\left\{\begin{array}{c}I_{s d}=\frac{\varphi_{s}}{L_{s}}-\frac{L_{m}}{L_{s}} I_{r d} \\ I_{s q}=-\frac{L_{m}}{L_{s}} I_{r q}\end{array}\right.$

Relations between the stator and rotor currents powers:

$\left\{\begin{array}{l}P_{s}=V_{s d} \cdot I_{s d}+V_{s q} \cdot I_{s q} \\ Q_{s}=V_{s q} \cdot I_{s d}-V_{s d} \cdot I_{s q}\end{array}\right.$

The adaptation of these equations axis system chosen and the simplifying assumptions made in this case $\left(\mathrm{V}_{\mathrm{sd}}=0\right.$ et $\left.\mathrm{V}_{\mathrm{s}}=\mathrm{V}_{\mathrm{sq}}\right)$ given:

$$
\left\{\begin{array}{l}
P_{s}=V_{s} \cdot I_{s q} \\
Q_{s}=V_{s} \cdot I_{s d}
\end{array}\right.
$$


By replacing the stator currents by their values we get the expressions:

$\left\{\begin{array}{c}P_{s}=-V_{s} \frac{L_{m}}{L_{s}} I_{r q} \\ Q_{s}=\frac{V_{s}^{2}}{L_{s} \omega_{s}}-V_{s} \frac{L_{m}}{L_{s}} I_{r d}\end{array}\right.$

Relations between rotor and rotor currents tensions:

One could express the rotor voltages depending on rotor currents, we can write:

$\left\{\begin{array}{c}V_{r d}=R_{r} I_{r d}+\left(L_{r} \frac{L_{m}^{2}}{L_{s}}\right) \frac{d}{d t} I_{r d}-g \omega_{s}\left(L_{r}-\frac{L_{m}^{2}}{L_{s}}\right) I_{r q} \\ V_{r q}=R_{r} I_{r q}+\left(L_{r} \frac{L_{m}^{2}}{L_{s}}\right) \frac{d}{d t} I_{r q}+g \omega_{s}\left(L_{r}-\frac{L_{m}^{2}}{L_{s}}\right) I_{r d}+g \frac{L_{m} V_{s}}{L_{s}}\end{array}\right.$

In steady state, the terms involving derivatives disappear, we can write:

$\left\{\begin{array}{c}V_{r d}=R_{r} I_{r d}-g \omega_{s}\left(L_{r}-\frac{L_{m}^{2}}{L_{s}}\right) I_{r q} \\ V_{r q}=R_{r} I_{r q}+g \omega_{s}\left(L_{r}-\frac{L_{m}^{2}}{L_{s}}\right) I_{r d}+g \frac{L_{m} V_{s}}{L_{s}}\end{array}\right.$

Vector control in stator wind power system based on a PI controller $[13,14]$ :

\subsection{Direct Vector Control}

This control mode ensures proper decoupling between flux and torque but the problem this disadvantage by the sensor. We neglect the terms of coupling between the two axes of control because of the low value of the slip. We are getting as shown in Figure 5.



Figure 5. Block diagram of the direct control

\subsection{Vector control indirectly}

The flow is controlled in open loop. It is not measured or estimated. The quantities (voltage or current) ensuring the flow direction and are evaluated 'decoupling from the equations of the machine transient.

The values of the rotor voltages depending on power and found we calculate:

$$
\left\{\begin{array}{c}
V_{d r}=g \omega_{s} \frac{\left(L_{r}-\frac{L_{m}^{2}}{L_{s}}\right)}{\frac{V_{s} L_{m}}{L_{S}}} * P-\left(\frac{R_{r}+\left(L_{r}-\frac{L_{m}^{2}}{L_{S}}\right)}{\frac{V_{s} L_{m}}{L_{S}}}\right) * Q+\left(\frac{R_{r} V_{s}}{\omega_{s} L_{m}}+\left(L_{r}-\frac{L_{m}^{2}}{L_{S}}\right) \frac{V_{S}}{\omega_{s} L_{m}} S\right) \\
V_{q r}=-\left(\frac{R_{r}+\left(L_{r}-\frac{L_{m}^{2}}{L_{S}}\right)}{\frac{V_{s} L_{m}}{L_{S}}} S\right) * P-g \omega_{s} \frac{\left(L_{r}-\frac{L_{m}^{2}}{L_{S}}\right)}{\frac{V_{s} L_{m}}{L_{S}}} * Q+g \omega_{s}\left(L_{r}-\frac{L_{m}^{2}}{L_{S}}\right) \frac{V_{s}}{\omega_{s} L_{m}}
\end{array}\right.
$$

The Figure 6 shown the isolation carried at the outputs of regulators in rotor currents without any return to the system. 


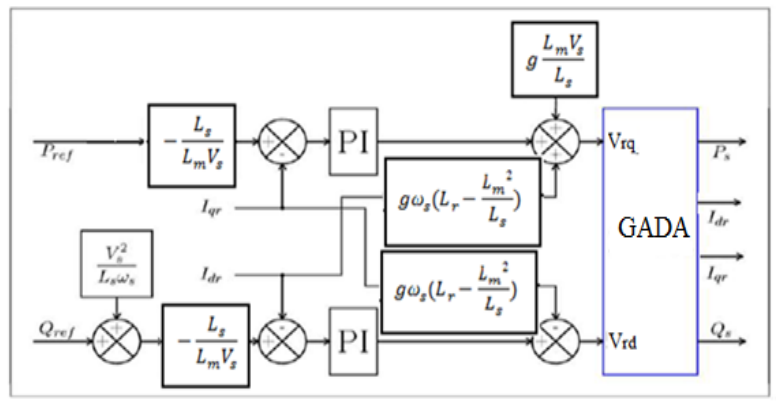

Figure 6. Iindirect command without power loop

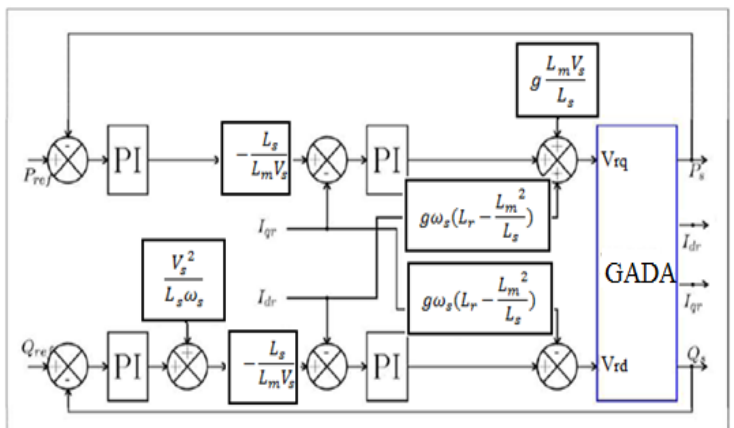

Figure 7. Iindirect control with power loop

The Figure 7 shown the method of control with power. In this method, the isolation is carried out at the outputs of the current regulators rotor with a return of the system.

\section{RESULTS}

To evaluate and test the indirect control technique with power loop of active and reactive power by the PI controllers, a simulation was performed under the MATLAB / Simulink. In this case, the gains of the PI controllers are based to method of design, which is based on the compensation of the time constant of the regulator with that of the process of the quantity to be regulated, and were refined after simulation:

a. For the power loop: $\mathrm{k} \_\mathrm{p}=75.75 ; \mathrm{K} \mathrm{i}=5354.55$.

b. For the current loop: $\mathrm{k} \_\mathrm{p}=75.75 ; \mathrm{K} \_\mathrm{i}=5354.55$.

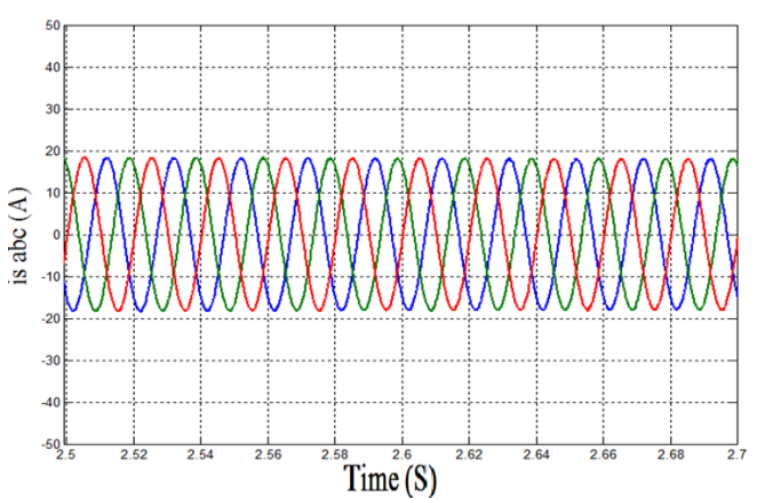

Figure 8. Stator current



Figure 10. Speed wind



Figure 9. Rotor current

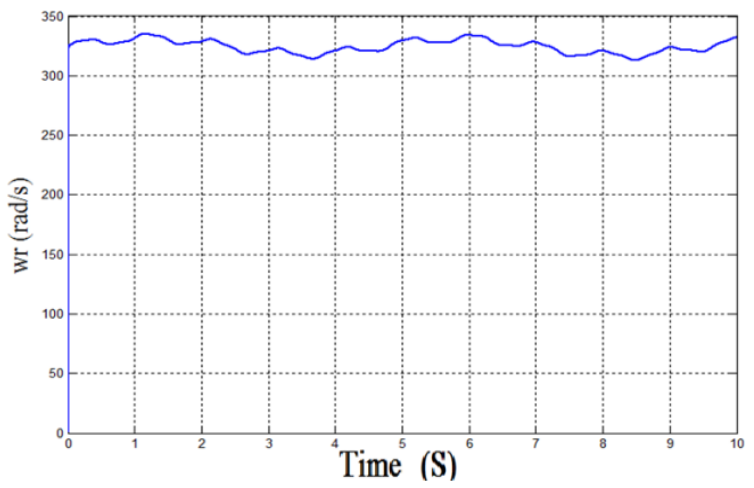

Figure 11. Rotor Speed 


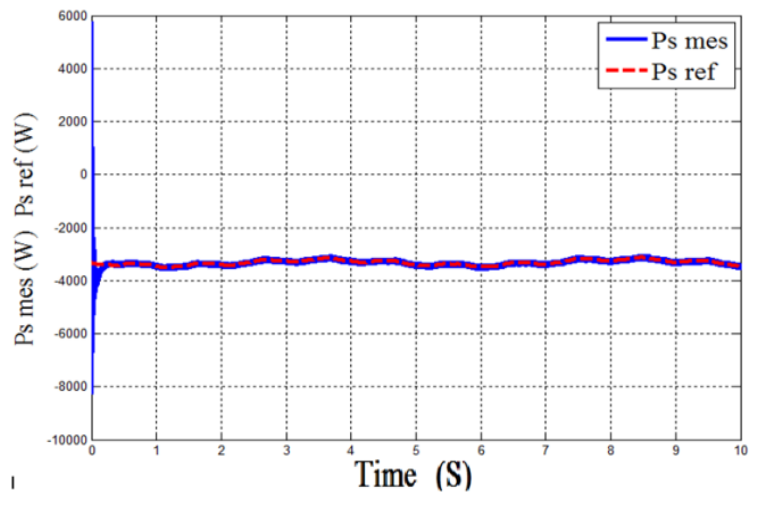

Figure 12. Stator active power

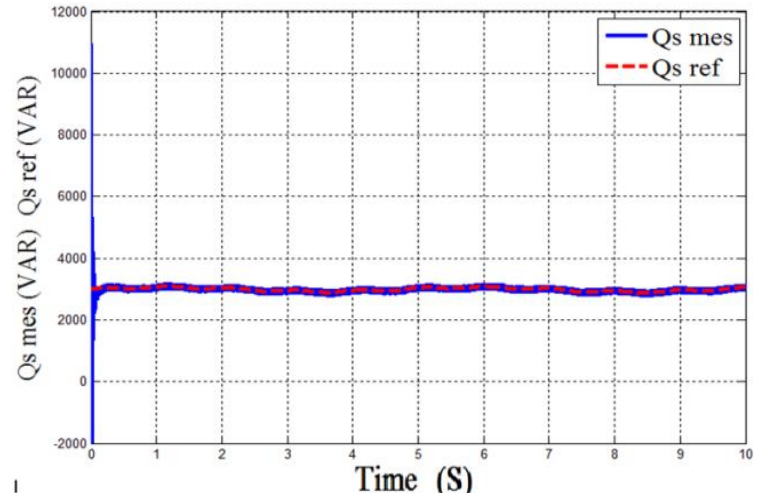

Figure 13. Stator reactive power

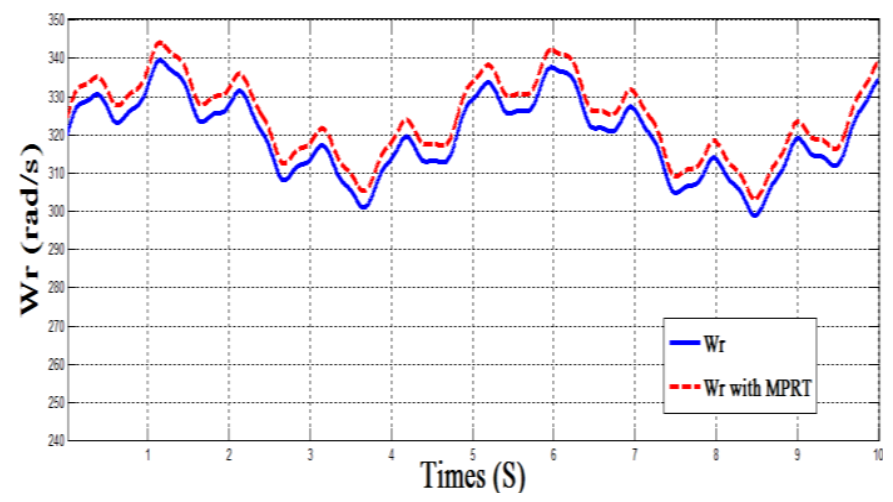

Figure 14. Comparison between Wr and Wr with MPPT

\title{
6. DISCUSSION
}

We obtained good results in dynamic handling and response to regulations imposed and reactive power. The fluctuations in the power due to the PWM inverter and the dependence of these powers slip. The figure 7 and 8 shown the results of the stator current and rotor current that have the same paces with the trend of the wind and the power. Are sinusoidal, implying a clean energy without harmonics supplied or absorbed by the DFIG.

The results obtained in Figure 12, 13 and 14, we can conclude that this type of control is more efficient than direct control in terms of a variable speed operation, since it is able to provide a decoupled control of active power and responsive regardless of the drive speed.

\section{CONCLUSION}

This paper present the modelling of the various components of a wind system for distributed generation of electricity and the study of different double-fed asynchronous machine control systems (DEIG) representing generator for production this energy. In the second part, we have begun the maximum power extraction technique in the operation of the wind; this method proves and gives good results for the maximum generated power to the grid. Subsequently, we developed vector of control reactive power in the stator level, the proper follow instructions for the two powers by the real powers debited by the stator of the machine showed the effectiveness of the applied control.

\author{
NUMENCLATURE \\ DFIG Doubly Fed Induction Generator \\ $\rho \quad$ Air density
}



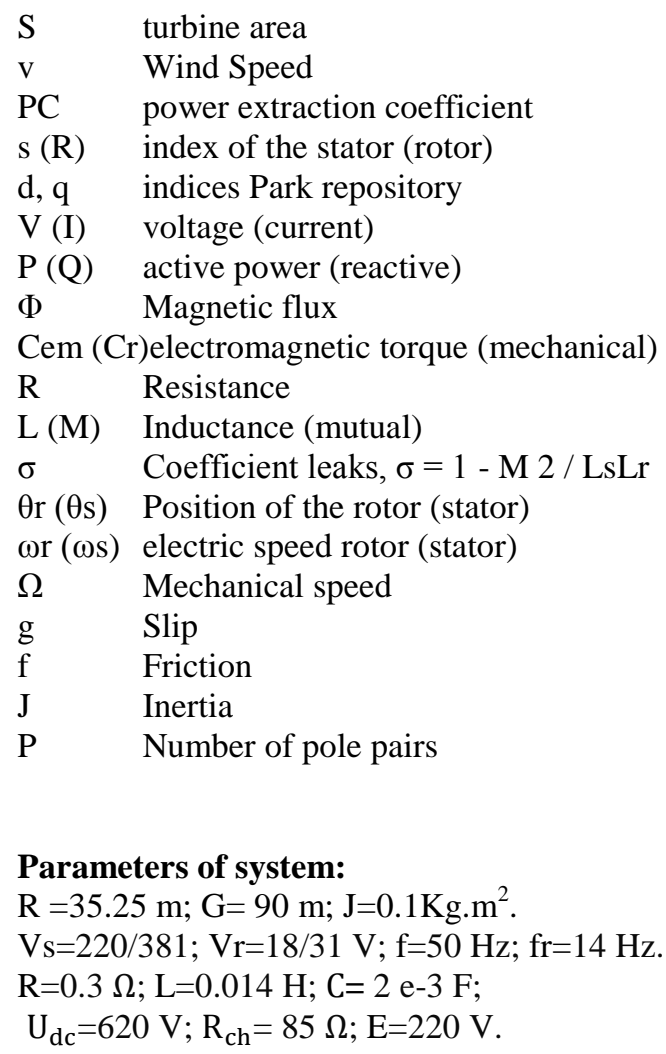

\section{REFERENCES}

[1] A. Harrouz, A. Benatiallah, O. Harrouz, "Modeling of small wind energy based of PMSG in south of Algeria", IEEE Explore, Second International Symposium on Environment-Friendly Energies and Applications (EFEA2012), Northumbrie University, UK. pp.191 - 195, 2012.

[2] A. Harrouz, A. Benatiallah, O. Harrouz. "Electric Control and Meteorological Validation of Sensors in Dynamic Metering System of Fluids", International Journal of Power Electronics and Drive System (IJPEDS), ISSN: 20888694, Vol. (3) No.4, Dec 2013, pp. 450-458.

[3] Hachemi Glaoui, Harrouz Abdelkader, Ismail Messaoudi, Hamid Saab, "Modeling of Wind Energy on Isolated Area", International Journal of Power Electronics and Drive System (IJPEDS), 10.11591/ijpeds.v4i2.4859, ISSN: 2088-8694, Vol. (4) No.2, JUIN 2014, pp. 274-280.

[4] A. Mirecki "Comparative chains of energy dedicated to a small wind turbine conversion study" Thesis in Electrical Engineering Laboratory and Industrial Electronics The ENSEEIHT, University of Toulouse April 5, 2005.

[5] L.Hamzaoui, "Modeling the dual asynchronous machine supply for use as wind turbine," Magister Thesis in Electrical Engineering, National Technical University, 20/01/2008.

[6] S. El Aimani, B. Francis F. Minne, B. Robyns, "Comparisonanalysis ofcontrol structures for variable speed wind turbine", Proceedings of CESA, 2003, Lille, France, in July 2003.

[7] F.Z.Arama, "Study and Control of asynchronous generator for the production of wind energy" Magister thesis in electrical Genie, National Technical University of Oran, Algeria, in 2013

[8] Slama El Magnet, "Modeling Different Aeolian Technologies Integrated into a network Average Tension," The School of Doctoral Thesis

[9] R. Abdessmed Mr. Kadjouj; "Electrical Machines Modelling", University Press of Batna, Algeria 1997.

[10] V. Paul-Etienne, "Order Non-Linear of Asynchronous Machine Dual Power", PhD in Electrical Engineering, National Polytechnic Institute of Toulouse, France, 2004.

[11] A.Chaiba, "Order of the asynchronous machine has dual power by techniques of artificial intelligence," Thesis in Electrical Engineering, University of Batna, Algeria, in 2010.

[12] A. L. Nemmour; "Contribution to the Vector Control of Asynchronous Machine Dual Power"; Magister thesis in electrical engineering, University of Batna, Algeria, 2002

[13] A.Mehdary "Emde chiane a wind energy conversion based on a AEROTURBINE". 6th Days of PhD students. Information science laboratory and LSIS systems. University of St. Jerome. Marseille. 2009.

[14] H. Becheri "Contribution to the sensorless control and maximum power search of a wind conversion chain" Magister Automatic Memory, University of Bechar, Algeria, in 2014.H.BECHERI «Contribution à la commande sans capteur et recherche de maximum de puissance d'une chaine de conversion éolienne» Mémoire de Magister en Automatique, Université de Bechar, Algérie, 2014. 